\title{
LA DISTRIBUCIÓN DE USO IS/SE EN LOS PROSISTAS LATINOS
}

\begin{abstract}
Against the old common opinion, the use of is/se for the Third Person Anaphora obeys to a well founded distribution in latin prose, if, on the one hand, we try to find the empractic situation underlying the production that the texts show, and, on the other, we respect the different blocks in the decursus. Then, it will appear a preference to Anaphora with se pointing to empractic First Person, or to Second Person, according to empractic meaning of each produced stretch.
\end{abstract}

La restricción que este título contiene se debe al hecho conocido en los poetas de su tendencia a evitar el uso de is, por lo que, si contáramos con ellos, quedarían desdibujados los límites en los que nos proponemos movernos. Esta cuestión, en efecto, debería ser objeto de un estudio aparte, si la referimos a los poetas, y sería susceptible de incluirse en otro mucho más amplio: las características del lenguaje poético.

Con esta primera medida aligeramos uno de los problemas de gramática latina que, a pesar de su carácter básico y de aparición cotidiana en cualquier texto que manejemos, no ha encontrado hasta la fecha, que nosotros sepamos, una explicación satisfactoria. En verdad no es de poca monta y de fácil tratamiento. Las numerosas anotaciones a pie de página, y no sólo en ediciones escolares, podrían por sí solas manifestarlo. Suelen aclarar que lo regular y esperado sería una forma de se cuando aparece una forma de $i$, y viceversa. Esto parece indicar que hay unas reglas para emplear unas veces se y otras is. Y que no se cumplen siempre. Los estudios sobre tales reglas sólo aparecen, hasta hace unos veinticinco años, en manuales.

Veamos lo que nos dice Tovar (1946, pp. 72-74): «El pronombre reflexivo... sirve como anafórico, es decir, remite al mismo sujeto de la oración... ha extendido su uso primitivo a ser sujeto... del verbo en infinitivo... Por el contrario, is sirve como anafórico en la oración simple para referir a un nombre que no sea sujeto... y también para remitir al nombre de una persona a que la oración principal se refiere, pero de la 
que la oración subordinada no representa el pensamiento." Tenemos que entender que, si representa el pensamiento de una persona de la oración principal, ha de emplearse se. Y así se expresa Ernout $\left(1942_{7}\right)$ en su edición revisada de la Sintaxis de Riemann; y cualquier otro manual, hasta el reciente de Scherer (1975).

La cuestión no suele tratarse tan escuetamente como hace Tovar. Vamos a examinar dos manuales que se preocupan bastante más de ella, aunque su postura difiera espectacularmente. La obra de ErnoutThomas $\left(1972_{2}\right)$ nos presenta una situación en la que, a tenor del tratamiento que hacen, hay más excepciones que reglas, con lo que se puede sacar la impresión, que expresamente manifiestan, de que los prosistas latinos, entre los que citan a Cicerón, sin ir más lejos, no se preocupan de respetar unas presuntas reglas ni de deshacer ambigüedades en numerosos pasajes de sus obras. La distribución de uso is/se les parece demasiado "souple» para mantenerla con diligencia, sobre todo, claro está, en la lengua vulgar.

Nos advierten que en las presuntas reglas no entran los casos de fórmulas con per, zon propter, construcciones con cum; ni el uso abundantísimo de suus para subrayar una oposición. Y que, por otra parte, la referencia mediante se puede dirigirse a un elemento de la propia oración que no sea el sujeto gramatical (lo que suele entenderse por tal, aclaramos nosotros). Lo llama Ernout sujeto «real». Otros lo adjetivan de otra manera: lógico, psicológico... Sujeto «pensante» lo llama Ronconi (1959, p. 117). Son casos como:

Liu., I 5,5 Iam inde ab initio Faustulo spes fuerat regiam stirpem apud se educari.

$\mathrm{Y}$ añade Ernout una especie de interpretación entre paréntesis: Faustulus sperauerat. No es la única vez que recurre a esto, y con frecuencia lo hace Kühner $(1966=1912)$. Es muy interesante y revelador.

En cambio, el manual de Kühner-Stegmann, al que acabamos de aludir, considera el uso de is como algo en cierto modo residual respecto al de se. Trata Kühner de defender a toda costa unas reglas que va presentando a lo largo de su exhaustiva exposición. Lo que más fácilmente se detecta en ella (también en Ernout) es una preferencia por el uso de se para la referencia anafórica. Preferencia ostentosa, de forma que, al terminar con el tratamiento del llamado reflexivo directo (cuando se apunta a un término de su oración; frente al indirecto, cuando apunta fuera de su oración), trata el uso de is brevísimamente, diciendo que se da cuando no hay ninguna relación reflexiva, sino que se refiere a algo opuesto y ya mencionado. 
Y también, al igual que Ernout, a los efectos de la referencia con se el sujeto puede ser gramatical o lógico.

Resumiendo, mientras que Kühner adopta la postura de intentar explicar todas las posibles transgresiones a unas pretendidas normas, intento meritorio que no evita una sensación de desobediencia a ellas, Ernout pone tanto empeño en ver infracciones que hace inútil el comienzo de cualquier exposición razonada.

Añadamos, también sintéticamente, las notas comunes a toda la bibliografia no reciente que ha tratado la cuestión que nos ocupa:

1) Relación entre el uso del reflexivo indirecto y el discurso indirecto. Woodcock (1971), no obstante, admite el primero sin que la oración subordinada presente la forma del segundo.

2) Separación en el tratamiento de se y de suus; atribuyendo al último un uso más libre, debido a su frecuente valor enfático, con lo que se hace jugar a la semántica.

3) Separación entre el lenguaje popular y el literario, bien para señalar la influencia del primero sobre el segundo', bien para advertir que aquél no puede mantener la complicada trama de éste, tal como aseguran, junto a Ernout, Stolz y Schmalz $\left(1910_{4}\right)$.

4) La asimilación al llamado sujeto gramatical de otros (¿no gramaticales?) a los efectos del uso de se. Woodcock nos habla de «the person or thing which is the centre of the thought».

5) La equiparación de algunas subpredicaciones a elementos frásticos habitualmente considerados de rango superior, al menos a los efectos del uso de se.

6) La intervención de la mente del autor (quitando protagonismo a sus personajes, añadimos nosotros), proporcionando al mensaje un "colorido objetivo".

Nuestra hipótesis de trabajo no puede ser otra que la de que los prosistas latinos mantienen una regularidad en el uso de is/se para la referencia anafórica. No puede admitirse que no se preocuparan de evitar ambigüedades. ¿Cómo puede concebirse que Cicerón, el acusado más conspicuo, emita un mensaje confuso en sus obras filosóficas por culpa, no del contenido, que sería más justificable, sino por descuido en el uso de reglas gramaticales? Y César, ¿echaría a perder su propaganda política por falta de claridad en la exposición de sus logros militares o de sus razones para iniciar una guerra civil?

Procederá, entonces, formular las reglas en otros términos, algo que ha intentado alguno de los estudios más recientes; porque, desde luego,

${ }^{\prime}$ En ello insiste especialmente Szantyr (1965). 
en todos los consultados ${ }^{2}$ hay una línea argumental, sin limitarse a exponer una sucesión de reglas y excepciones, que defiende la sistematicidad del uso de is/se.

La verdad es que hasta unos diez o doce años este problema de gramática latina apenas se ha tocado. $\mathrm{Y}$ tenemos que prescindir de las aportaciones de G. Giannecchini (1980-1981), que viene a coincidir algo con los errores que hemos detectado hasta ahora, y de las de Orlandini (1987), Dahlén (1964) y Serbat (1984), que no lo tratan de lleno ${ }^{3}$.

Tal vez podrían considerarse aparte los trabajos de A. Bertocchi y C. Casadio. Podemos prescindir del de 1980 y referirnos sólo al de 1983. Parten de los postulados del generativismo, cuya teoría de la opacidad se ve amenazada por el estatuto del reflexivo indirecto latino. Para salvarla proponen la teoría chomskiana de la «Rección y el Ligamiento", que, mediante el concepto de categoria de rección (que incluiría otro, el de categoría mínima de rección) y la intervención de un índice aplicable al pronombre, nos daría la distinción entre "proximate pronoun" (el se latino, en este caso) y "obviative pronoun» (is).

A pesar de partir también de los principios de la GGT, mejor planteado y mejor resuelto nos ha parecido el trabajo de Elena Benedicto (1989). Pero creemos que en ambos casos se peca de lo mismo, de abordar hechos gramaticales aplicándoles estructuras de teorías a manera de ciencia, es decir, de hacer entrar hechos de lenguaje en esquemas que le son externos.

Mucho más interesante es el estudio de M. Fruyt (1987). Ya supone un avance su propósito de explicar lo que se consideraban irregularidades. Reconoce que con su enfoque aún quedan algunas sin explicar (p. 213), pero del conjunto de aquél puede deducirse que también éstas (sacadas de pasajes de César) deberían explicarse, aunque con otros razonamientos (alguno propone). No hay para ella, pues, arbitrariedad ni despreocupación.

Parece que su intención primordial es explicar por qué el reflexivo no apunta siempre al sujeto gramatical.Y lo hace a través de un enfoque que denomina semántico-referencial, según el cual no ha de considerarse el sujeto gramatical en el mensaje (interpretación sintáctica), sino el locutor de la enunciación, que sería el término anaforizado, fuera cual fuera su función sintáctica, por el reflexivo. Creemos que tal concepto es algo vago $\mathrm{y}$, al tiempo, aplicable a un campo reducido.

Mucho más aprovechable es el magnífico trabajo de Milner (1978).

${ }^{2} \mathrm{Y}$ que tratan realmente la distribución de uso is/se.

${ }^{3}$ Sí se acerca aceptablemente Anna M. Orlandini en un trabajo posterior (1989). 
Así cuando habla de que, a diferencia de las lenguas modernas, la tercera persona indoeuropea era una auténtica persona, implicada en el mensaje; no como lo están la primera y la segunda, sino sólo por el hecho de estar mencionada en él. Lo que ocurre es que, si se produce un cambio en las condiciones de la enunciación, las vicisitudes de las dos primeras personas pueden seguirse por las condiciones del diálogo, mientras que la referencia de la tercera persona ide. es más problemática, puesto que puede haber más de un término mencionado. Para solucionar el eventual conflicto acude a lo que para él es la clave: la noción de dimensión enunciativa. Dentro de esta dimensión, el enunciador puede considerar un término como distinguido. Mientras que en las lenguas modernas, afirma, aquélla se formaliza en la unidad sintáctica que llamamos frase y el término distinguido en ella es el sujeto, no sucede lo mismo en latín.

Lo malo es que, al aclarar qué entiende por término distinguido, senala que es aquel que el sujeto hablante escoge como tal, con lo que no supone un apoyo definitivo si está pendiente del concepto de sujeto hablante, tan equívoco en el mejor de los casos.

Serbat (1988) no habla para nada de la concurrencia de is (pronombre que es el único que trata) con se; pero parte de principios y conceptos muy útiles, como su noción de "escala de subjetividad» y de «situación de enunciación"».

Lo expuesto en estas primeras páginas nos basta para informarnos bien del estado de la cuestión; y a nosotros, concretamente, los mismos errores que nos parecían cometer los estudiosos que nos han precedido nos abrían los ojos a una posible solución. En efecto, a medida que íbamos viendo la imposibilidad de dar con una explicación plausible y global de este hecho de gramática latina, aun partiendo de enfoques diversos, como ocurría con buena parte de los autores hasta ahora vistos, más nos convencíamos de la necesidad de llevar a cabo un estudio verdaderamente gramatical, es decir, había que intentar descubrir lo que había por debajo de esa superficie que llamamos distribución de uso de is/se en los prosistas latinos, cuáles eran los mecanismos que lo movían. Para lograrlo era necesario acceder a esa superficie sin ningún bagaje de prejuicios. Y de acuerdo con esta actitud, nos parecía que, de todo lo aportado por nuestros antecesores, había que someter a crítica tres puntos:

\section{La cuestión del sujeto}

El concepto de sujeto, tal como se ha presentado, es multívoco. 
¿Habria que entender por «sujeto» todas las cosas que se han dicho, y alguna más, o definirlo con otras notas, o considerarlo no válido?

$\mathrm{Si}$ se nos dice que el reflexivo puede apuntar a otro bloque de producción, la idea de sujeto parece aún más vaga. No digamos de la situación en que dos formas de reflexivo incluidas en un mismo bloque pueden apuntar a sujetos de bloques distintos. Casos como:

Curt., VIII 1,9 Scythae petebant ut regis sui filiam matrimonio sibi iungeret.

Es igualmente perturbador que la existencia de una preposición rompa la relación del reflexivo con el sujeto, irregularidad que señalan Ernout y Kühner (pp. 183 y 601, respectivamente):

Cic., Quir. 2 [liberi] mihi et propter indulgentiam meam et propter... eorum ingenium uita sunt mea cariores ${ }^{4}$.

Problemas plantean también los llamados verbos impersonales de sentimiento, aun contando con explicaciones como la de Enríquez (1984).

Pero hay más. Las excepciones a esta regla establecida sobre un concepto poco válido, el del sujeto, tratan de explicarse mediante nociones igualmente difusas, como la intervención del punto de vista del autor y el valor enfático, sobre todo en el posesivo suus. De la primera echa mano Kühner para justificar casos como:

Cic., Br. 220 orator uiuis eius aequalibus proximus optimis numerabatur,

frente a otros como:

Id., ibid. 281 inuitis suis ciuibus nactus est imperium.

El valor enfático justifica muchísimos más casos. Pero ya Kühner (p. 604) advierte que aparece también suus sin ninguna significación especial; y entonces el problema está en que no pueden establecerse criterios gramaticales en términos de más o menos. El decidirse por ver un valor enfático o todavía no, no responde a criterios gramaticales, sino estilísticos; lo cual no quiere decir que debamos prescindir de ellos, pero sí aplicarlos sólo en una segunda instancia.

4 Aunque Ernout añade: «c.-à-d. liberos existimo.» 
2. Relación entre el llamado reflexivo indirecto y el discurso indirecto

Es una relación que se mantiene en alguno de los estudiosos actuales, como es el caso de M. Fruyt.

Habría que reformularla diciendo que, en determinados casos, el «sujeto» de la oración principal sigue actuando lingüísticamente en la subordinada, cosa que no tiene por qué suceder siempre en una subordinada de las que llamamos de discurso indirecto; si es que no jugamos sólo con diferencias terminológicas. Por no tener claro esto Ernout presenta como irregulares pasajes como:

Plaut., Merc. 238-9 dicit capram quam dederam seruandam sibi, / suae uxoris dotem ambedisse.

$\mathrm{Y}$ es que eso de "representar el pensamiento" es algo difuso, poco apto para un estudio gramatical. Ya Milner (pp. 81-82) y Fruyt (p. 219) intentan explicar de otra manera este empleo de los modos, con mayor agudeza en Milner.

\section{Delimitación de los distintos bloques}

Es imprescindible para el estudio correcto del uso de is/se la delimitación correcta de los bloques en la producción y el admitir que, a los efectos de aquél, se equiparan a elementos de nivel oracional tenidos siempre como tales otros considerados de rango inferior: subpredicaciones, en general, y epítetos y aposiciones, en particular.

Parece que lo segundo se ha logrado casi siempre en los estudios habidos hasta el presente, como hemos reconocido en su momento.

Pero lo primero no siempre se hace. No lo hace, por ejemplo, Kühner con los dos pasajes del Brutus ciceroniano, 220 y 281 , y por eso tiene que acudir al expediente del punto de vista del autor. No hace falta: en uiuis eius aequalibus hay coma obligatoria, lo que quiere decir que eius es totalmente normal, de acuerdo con las reglas que tradicionalmente se admiten, puesto que apunta al sujeto (también según la concepción tradicional) de un bloque distinto. En cambio, en inuitis suis ciuibus la coma es potestativa $\mathrm{y}$, al no haber dos bloques distintos, suis apunta, como cabe esperar, al sujeto de nactus est.

Tras las precisiones anteriores, prosigamos actuando con la ratio que proponíamos. Lo primero que salta a los ojos para quien lea de primera intención textos latinos, pero también para quien consulte an- 
tes o después cualquier manual que trate la cuestión con cierto detenimiento, es que la referencia anafórica con se es muchísimo más frecuente que con is; siempre que la concurrencia sea posible. Respecto a los manuales consultados, ya hemos hecho notar tal hecho. Nos bastaria con citar la multitud generosa de ejemplos que aduce Kühner en su minuciosa exposición. Pero hemos querido contar también con cosecha propia.

En nuestra lectura del Jugurta salustiano no hemos encontrado un solo caso de referencia con is cuando se esperaba se (insistimos, según las reglas habituales). En realidad, apenas hay tres o cuatro pasajes que incluyan un uso de is como anafórico. En cambio, casos como:

64,2 debere illi res suas placere.

66,1 ciuitates quae ab se defecerant... adfectare,

aparecen por doquier.

Algo parecido ocurre con Catilina, aunque aquí contamos con un par de pasajes:

51,28 Lacedaimonii... triginta uiros imposuere qui rem publicam eorum [sc. Athenienses] tractarent.

56,5 Interea seruitia repudiabat, cuius initio ad eum [sc. Catilina] magnae copiae concurrebant ${ }^{5}$.

Como una de las causas que se pretextaban para los usos irregulares de $s e$ es el estilo de determinados autores, hemos querido aportar el dato y testimonio de uno alejado de Salustio en el tiempo y en el arte literario: la lectura del Tiberio de Suetonio nos ha proporcionado resultados muy similares a los de las dos obras salustianas ${ }^{6}$.

El material «heredado» de nuestros antecesores es precioso. Ellos han observado cómo se puede apuntar a todo tipo de "sujeto" y de caso oblicuo, y además existe no infrecuentemente una doble referencia dentro de un mismo bloque. A los pasajes aducidos por Ernout se podian añadir otros muchos, como:

Caes., B.G. I 36,4 Ariouistus respondit... magnam iniuriam Caesarem facere, qui suo aduentu uectigalia sibi deteriora faceret.

Liu., II 6,2 [Tarquinius] orare... ne se ortum eiusdem sanguinis... ante oculos suos perire sinerent.

${ }^{5}$ El tratamiento de las oraciones de relativo ha merecido una explicación por parte de Milner (p. 82).

${ }^{6}$ Otros autores leidos son Petronio, Justino, Curcio y Gayo. 
Ya hemos visto cómo se defiende y se ataca la preocupación de los autores latinos por evitar los mensajes ambiguos. Éste es otro criterio que se ha defendido como regla y que nosotros mismos, al principio, tuvimos en cuenta: el criterio de ambigüedad. Pues bien, incluso en casos en que se dice que hay ambigüedad, como:

Caes., B.G. II 21,2-3 Milites... cohortatus... uti suae pristinae uirtutis memoriam retinerent... signum dedit;

apunte a quien apunte suae, se emplea esta forma, no eorum o eius, que eliminarían la ambigüedad.

Y terminemos este apartado con dos pasajes ilustrativos:

Sall., Iug. 49,2 obtestatur uti memores... uirtutis sese regnumque suum defendant.

Id., ibid. 26,1 Italici... Adherbali suadent uti seque et oppidum Iugurthae tradat.

Es decir, se puede apuntar al locutor de la enunciación, pero también al interlocutor. Nada nos vale, pues, la aportación de Fruyt en este aspecto.

Es decisivo, en cambio, poner en contacto este dato incontrovertible que acabamos de desarrollar con otro expuesto algo más atrás: la inutilidad del concepto de sujeto; al menos en el ámbito en que ahora nos movemos. Más que dos datos parecen manifestaciones distintas de un mismo hecho. $\mathrm{Y}$ si el sujeto es algo que no interviene en la distribución de uso de is/se es que, en efecto ${ }^{7}$, no cabe del hecho una interpretación sintáctica.

Pero no acudamos a lo semántico, como hace Fruyt, que es siempre peligroso para un estudio gramatical. Recordemos mejor que en una tesitura empráctica del acto de lenguaje ${ }^{8}$ no hay sujeto ni nada que se le parezca, sino sólo personas actuando lingüísticamente, protagonistas de la acción lingüistica, primeras y segundas personas.

${ }^{7}$ Milner habla (p. 84) de un criterio interpretativo, dependiente de las condiciones particulares de cada enunciación.

${ }^{8}$ En terminología de Bühler. Pueden leerse a modo de introducción algunas páginas de su Teoria del Lenguaje (1967, ): 96-99, 101, 115-122; con datos más concretos en 241-245; también 525 y 550-558. Menos útiles a nuestros propósitos son sus consideraciones sobre la anáfora en p. 561 ss.

Nos interesan más, porque descienden más a lo concreto, las nociones que expone García Calvo en Del lenguaje, I, Madrid 1979. Clave es su distinción "mundo en que se habla" / «mundo de que se habla». Vid. pp. 333, 338, 342-3, 347-8, 361, 368, 377, 396 ss., 352, 177-181 y 198-9; y en De la construcción, Madrid 1983, pp. 212-3 y 404-5. Aunque esta consideración pragmática del lenguaje esta presente a lo largo de estas dos obras suyas. 
Nuestra propuesta, por consiguiente, es que el se latino apunta a protagonistas de la acción lingüística. Por eso su uso es perfectamente normal en todos los ejemplos presentados hasta ahora, incluidos los dos últimos de Salustio, en los que se se dirige a la primera en 49,2 y a la segunda en 26,1 . Pero nos estamos refiriendo a la primera y la segunda emprácticas, que no han de estar por fuerza marcadas morfosintácticamente. Concretamente, se puede apuntar a la primera o a la segunda o a ambas, como hemos visto en los bloques con doble referencia.

Lo que acabamos de formular explica que, si no se enfoca así la referencia anafórica en los prosistas latinos, haya siempre problemas con el llamado sujeto y que, aun en el caso hipotético de que corresponda a algo que sea definible en sintaxis o en semántica, a pesar de las piruetas que se realizan adjetivándolo de varias maneras, se tengan que admitir numerosas excepciones, con nuevas piruetas para justificarlas ${ }^{9}$. Nada extraño resulta, pues, que el primer movimiento sea el de rechazo a admitir una distribución regular del uso de is/se.

Pero si partimos de las precisiones y observaciones que hemos ido haciendo, podremos comprobar que los prosistas manejados por cualquiera de los estudiosos que nos han precedido en esta cuestión reflejan en su uso de la anáfora el mantenimiento de una conciencia de una situación empráctica a la hora de escribir sus obras, una situación en que las subpredicaciones no han alcanzado todavía un grado de sintetización como para que el protagonismo de la acción lingüística pase a un término del núcleo de la frase al que se adhirieron o sintetizaron posteriormente. Por supuesto que hay grados y etapas en esa sintetización ${ }^{10}$, y de ahí el carácter potestativo u obligatorio de las comas que hemos señalado a propósito de los dos pasajes del Brutus ciceroniano. En el Pro Milone 39 eius apunta a la segunda persona del bloque imploranti. Precisamente suam sí que provocaría cierta ambigüedad.

La mentada ambigüedad sólo puede constituir un criterio válido, creemos, si se aplica supletoriamente y dentro de ese marco general que hemos diseñado: preferencia por el uso de se apuntando a personas de la acción lingüística. Ello supone que no podemos dejar aquí la descrip-

${ }^{9}$ Como hace Kühner, el más aficionado a ellas, para explicar, por ejemplo, el conflictivo pasaje presentado también por Ernout, quien no le encuentra explicación:

Cic., Mil. $39 \mathrm{Cn}$. Pompeius... cunctae Italiae cupienti et eius fidem imploranti signum dedit.

${ }^{10}$ Ya Kühner distingue entre «innerlich abhängigen, d.h. solchen Nebensätzen welche nicht als Gedanke des Schriftstellers, sondern aus der Seele eines anderen, besonders des Subjekts des Hauptsatzes ausgesprochen" y las "nicht innerlich abhängigen Sätzen", en las que se emplea is, frente a las anteriores, en las que se emplea se. 
ción del uso de is/se. Si el único principio rector fuera esa preferencia de $s e$ sobre is, el criterio de ambigüedad no sería supletorio, sino determinante, con lo que no tendría sentido pensar en reglas gramaticales. Pero tiene que haberlas, si seguimos pensando que no había despreocupación por las expresiones ambiguas. Y desde luego el criterio de ambigüedad es inútil en pasajes como el de César, B.G. II 21,2-3, como advertimos en la presentación de este ejemplo. Y si, como parece, interpretamos bien los pasajes del Jugurta 49,2 y 26,1 , ocurriría lo mismo, puesto que en una de las dos frases tendría que emplearse una forma de is. Pero se emplea se en las dos $\mathrm{y}$, sin embargo, no hay ambigüedad. Luego no basta contar con esa preferencia de se para apuntar a las personas de la acción lingüística, sino que hace falta precisar cómo se actualiza esa preferencia. Veámoslo.

Dado que los prosistas latinos que venimos estudiando conservan en sus actos de lenguaje, como hemos hecho notar, una situación empráctica, en la que sólo habría personas actuando, unas veces hablando, otras mandando y/o recibiendo órdenes, otras conjurando, deseando..., podríamos reflejar esa situación de una manera más inmediata a nuestra mentalidad cotidiana represéntandola por medio de citas. Pues bien, esas citas se formalizarian en frases de modalidad lógica, yusiva o votiva, básicamente. Con ello ya se ve bien que, cuando decíamos que se apuntaba a personas emprácticas, estábamos refiriéndonos a primeras y segundas personas de estas frases originarias inducibles de las actuales. Ellas nos recuerdan que el lenguaje no siempre hace lo mismo (puesto que aquí no nos referimos al lenguaje instrumento), cosa que influye en la dirección a donde apunta se.

Así las cosas, se puede observar que:

A. Cuando la acción lingüística se pueda representar por medio de una frase de modalidad lógica:

a. Se apunta a la primera persona en esa frase:

Suet., Tib. 3,2 Salinator uniuersas tribus... notauit..., quod, cum se... condemnassent, consulem iterum... fecissent.

Id., ibid. 20 Batonem... transtulit, gratiam referens, quod se... passus esset euadere,

un buen ejemplo para no confundir la persona empráctica con la sintáctica. Por eso no se puede decir que se emplea se cuando «el sujeto del infinitivo es el mismo que el del verbo principal», como aparece aún en algunas gramáticas escolares. 
b. Se apunta a la segunda en tal frase (pero no obligatoriamente):

1. Cuando la primera está marcada morfosintácticamente:

Plaut., Merc. 903-4 quem ego hominem, si quidem uiuo, uita euoluam sua / sed ego stultus sum, qui illius esse dico quae meast

(el contenido del 904 es revelador).

2. Pero lo más frecuente es que esté marcada emprácticamente:

Caes., B.G. I 47,1 Ariouistus ad Caesarem legatos mittit... e suis legatis ad se mitteret.

Pero, como decimos, no es obligatorio, y por eso, al lado de este pasaje de César, podemos encontrarnos alguno como:

Sall., Iug. 102,2 legati... regis uerbis ab Mario petiuere duos... ad eum mitteret: uelle de se... cum eis disserere.

Con mucho más motivo podría emplearse se para apuntar a segunda cuando no hubiera primera, pero esta situación no se dará con frecuencia, sobre todo en autores como César, con intenciones de «escenificar». Y si, por el contrario, no hay conciencia ni deseo de mantener la tesitura empráctica, mal podrá emplearse se cuando no hay personas. Con todo, esa conciencia está tan presente, que permite casos como:

Petron., 43,1 ille habet quod sibi debebatur

Sall., Iug. 3,3 nisi forte quem... lubido tenet... libertatem suam sacrificari,

es decir, contextos susceptibles de conservar la situación primitiva, sobre todo los que mantienen un aire de máxima o refrán:

Liu., XXIX 37,11 Aeque foedum certamen inquinandi famam alterius cum suae damno factum est.

Todas estas razones explican el dato observado de un mayor uso de se que de $i s$, obtenido con una simple ojeada a la gramática de Kühner. Is se utilizará menos: potestativamente en los casos en que se es potestativo, pero obligatoriamente en los casos en los que, por no estar marcada la primera de las dos maneras, la acción lingüística se presentaría confusa ". En esos casos, is apunta a la segunda:

1 Asi debería formularse el criterio de ambigüedad. 
Suet., Tib. 5,1 At illa... de intolerantia morum eius... recitauit.

Sall., Cat. 40,3 accusare senatum quod in eo auxili nihil esset, miseriis suis remedium mortem expectare.

Este empleo de is nos aclarará la situación o el acto de lenguaje correctamente, pero podrá servir también para una correcta delimitación de los bloques de simultaneidad:

Suet., Tib. 32,2 Diogenes... uenientem eum, ut se extra ordinem audiret... per seruolum suom distulerat...; hunc... salutandi sui causa... adstantem... admonuit,

o más claro:

Caes., B. G. I 6,3 Allobrogibus sese uel pesuasuros... existimabant uel ui coacturos ut per suos fines eos ire paterentur.

Permitásenos insistir en dos puntos antes de pasar al apartado B: En primer lugar, abundar en el hecho de que la cuestión de la actuación lingüística de las personas emprácticas no puede separarse en la práctica de la cuestión de los bloques, aunque en su momento lo hayamos hecho por razones de orden y claridad expositivos. Cualquier pasaje de los dos utilizados nos podría servir de ejemplo, pero véanse otros como:

Suet., Tib. 74,1 Apollinem... uiderat per quietem affirmantem sibi non posse se ab ipso dedicari,

y otro, que concernirá también al apartado B:

Cic., Att. XV 21,1 scripsit filius se idcirco profugere ad Brutum uoluisse quod, cum sibi negotium daret Antonius ut eum dictatorem efficeret, id recusaret.

En segundo lugar, reincidir en que la situación empráctica en estos autores está más presente de lo que pueda parecer a primera vista; aunque no parece que nosotros hayamos perdido del todo esa conciencia y por eso podemos apreciarla en casos como:

Liu., I 5,5 Iam inde... Faustulo spes fuerat regiam stirpem apud se educari

(recuérdese la aclaración de Ernout: Faustulus sperauerat).

Pero hay que prestarle la debida atención, para que en pasajes como:

Caes., B. C. III 28,4 tirones... iureiurando accepto nihil iis nocituros hostes se Otacilio dederunt,

en el que iis es normal, puesto que apunta a segunda en el bloque iureiurando nocituros, de manera que la cita podría ser algo como «nos- 
otros los enemigos, os juramos que no os haremos daño", no veamos irregularidad.

B. Cuando la acción lingüística se pueda reflejar en una frase de modalidad yusiva:

a. Se apunta a la segunda, cosa totalmente esperada, dado que es en este tipo de frases donde surgen las segundas personas. La preferencia es, pues, la inversa de la descrita en el apartado A y el uso potestativo de se/is estará establecido en las mismas condiciones. Por tanto:

Cic., Verr. II 85 [Verres] a Sthenio petere coepit ut ad ea tollenda operam suam, profiteretur,

y muchos pasajes más, como los ya presentados de Caes., B.G. II 21,2 (al que añadimos ahora I 40,4 cur de sua uirtute aut de ipsius diligentia desperarent), Sall., Iug. 26,1, etc., pero también cualquiera de los aducidos por Kühner en p. 609,7 .

Mientras que

b. se puede apuntar a primera, si la segunda se presenta marcada formal o emprácticamente:

Cic., Verr. IV 27 [Heius] respondit istum ad se misisse ut sibi mitteret peripetasmata.

Sall., Cat. 31,7 postulare a patribus coepit ne quid de se temere crederent... $\mathrm{Ne}$ existumarent sibi... perdita res publica opus esse.

Las mismas advertencias que hemos hecho en el apartado A serán aplicables ahora al carácter potestativo del uso de is, en lugar de se, para apuntar a primera, aun teniendo en cuenta la poca probabilidad de que se dé una frase de modalidad yusiva que no contenga una segunda persona marcada, al menos, emprácticamente. Pero si la situación es ésa y no se viera claro el juego de los protagonistas, is apunta a primera:

Cic., Verr. I 86 Milesios nauem poposcit quae eum praesidii causa Myndum prosequeretur,

es decir, un pasaje que Ernout (p. 185) utiliza para acusar a Cicerón de poco cuidadoso. $\mathrm{Y}$ resulta ser lo contrario ${ }^{12}$. $\mathrm{Y}$ al igual que advertía-

12 Al igual que en los dos ejs. de Petronio, que aduce para asegurar que la lengua popular no alcanzaba a dominar la sutileza del empleo del reflexivo: 43,1 ille habet quod sibi debebatur, frente a 38,4 scripsit ut illi ex India semen boletorum mitteretur. Quedan ahora perfectamente explicados y justificados. 
mos en el apartado anterior, aquí is y se servirian, de paso, para deslindar mejor los bloques, como en:

Caes., B.G. I 5,4 Persuadent... Latobicis finitimis suis uti eodem usi consilio, oppidis suis uicisque exustis, una cum iis proficiscantur.

C. Si la situación fuera representable por medio de una frase de modalidad votiva, en la que debemos pensar que las personas emprácticas quedan al margen de la acción, lo que se espera es que aparezcan referidas por $i s$, al aparecer únicamente como mencionadas. Y, en efecto, lo que hay son casos como:

Caes., B.C. III 30,5 ignesque fieri prohibuit quo occultior esset aduentus eius.

Cic., Diu. I 3 [Romani] omnes hanc ex Etruria scientiam adhibebant, ne genus esset ullum diuinationis quod neglectum ab iis uideretur.

Front., Str. II 4,8 Marcellus cum uereretur ne paucitatem militum eius clamor detegeret...

Finalmente, se puede considerar rara la confluencia o cruce de modalidades, que provocaría casos conflictivos, muy escasos, como:

Iust., III 3,11 iure iurando obligat ciuitatem nihil eos de eius legibus mutaturos.

Nep., XXIII 12,2 Patres conscripti... legatos in Bithyniam miserunt... qui ab rege peterent ne inimicissimum suum secum haberet sibique dederet.

Hay un comportamiento del uso de is/se que, aun sin salir de esta esfera de lo empráctico, presenta una particularidad digna de estudio. Se da ésta cuando hay dos referencias, más frecuentemente en bloques distintos, a un mismo término. Si la primera referencia se hace por medio de se, la segunda se hará con is; y viceversa. La causa parece clara: si la primera referencia se formaliza con se, referente de personas privilegiado, la segunda supondrá un hablar de una persona de la acción y, por tanto, se considerará ya como no persona, por lo que se empleará el referente más adecuado, is. $\mathrm{Si}$, por el contrario, la primera se hace con is, se considera que esa no persona ha quedado introducida ya en el campo y será apta para ser persona, por lo que la segunda referencia se hará mediante el referente de persona, $s e$.

Cierto es que hay algunos casos en los que se podía buscar otra explicación, como:

Cic., Off. I 108 Solo, quo tutior uita eius esset, furere se simulauit

(modalidad votiva en el bloque de esset). 
Pero es que hay otros, bastantes, en los que no parece verosímil otra explicación, demasiados como para no pensar en un hecho sistemático. Veamos, por ejemplo:

Plaut., Capt. 580 is est seruos ipse neque praeter se ei unquam seruos fuit.

Sall., Iug. 64,2 debere illi res suas placere.

Cic., Sull. 88 huic puero qui est $e i$ uita sua carior...

B.Alex. 32,2 neque eum consilium suum fefellit.

Cic., Pro Rab. Post. 43 nec illius animi aciem praestringit splendor sui nominis.

Tac., Dial. 13 licet illos certamina... sua... euexerint.

En los que las dos referencias aparecen en el mismo bloque. Y aparece ille por is ${ }^{13}$.

$\mathrm{Y}$ en bloques distintos:

Suet., Tib. 72,2 Erat ei draco quem manu sua cibaturus [donde podria haber énfasis en sua, pero no es el caso del ejemplo siguiente].

Cic., De or. I 232 Quod cum interrogatus Socrates esset, respondit sese meruisse ut... et ut $e i$ uictus... praeberetur.

Caes., B.G. V 27,2 Ambiorix... locutus est: sese pro Caesaris in se beneficiis plurimum $e i$ confiteri debere, quod $e i$ et filius et fratris filius a Caesare remissi essent [pasaje admirable].

Caes., B.G. I 11,3 Haedui legatos... mittunt...: ita se... meritos esse ut... liberi eorum... abduci non debuerint.

La verdad es que esto ya lo había observado (aunque no aplicado) Kühner.

¿Debe dedicarse un apartado especial al posesivo suus? Suele hacerse, incluidos los estudios más recientes. Pero no parece que el estatuto de suus sea diferente al de se en su empleo frente a is. Ahora bien, deberíamos esperar algunas diferencias (no nos atrevemos a llamarlas cualitativas). Hay que recordar, en efecto, que la posesión puede formalizarse en latín diferentemente y con diferentes grados. Es lógico, por tanto, que su formalización con suus pueda, según sea la tesitura empráctica, tener una marca muy llamativa. Así en:

Suet., Tib. 61,2 damnatique multi cum liberis atque etiam a liberis suis.

¿Podría haber surgido de aquí la evidente lexicalización de suus? Podría estar provocada también por la estructura en contraposición de la frase:

Cic., N.D. II 32 placet duos esse motus, unum suum, alterum externum,

${ }^{13} \mathrm{Y}$ por otra pieza que alcance la misma función que is o ille, como en Cic., Mil. 81 cuiquam salus sua non probari. 
que se da más leve en:

Caes., B.G. I 36,1 item populum Romanum uictis non ad alterius sed ad suum arbitrium imperare consuesse

(aquí la contraposición y lexicalización impiden la ambigüedad, pues está hablando Ariovisto).

La contraposición puede establecerse de formas más sutiles:

Cic., Off. II 73 ut sua tenerentur res publicae constitutae sunt.

Liu. IV 33,5 suis flammis delete Fidenas, quas uestris beneficiis placere non potuistis.

Y una vez instalada en el sistema la lexicalización podemos llegar a pasajes en los que se dice que hay énfasis en el posesivo:

Cic., Sest. 142 hunc sui ciues... eiecerunt,

una vez que la lexicalización es moneda corriente, como se ve en:

Virg., Aen. V 832 sua flamina,

que M. Rat traduce por «souffles propices».

Lo del énfasis o no es cuestión sólo de más o menos $\mathrm{y}$, por tanto, inservible gramaticalmente.

La lexicalización de suus (y también de se) que vemos en pasajes como:

Nep., I 1,1 de eo... confidere ciues possent sui,

puede lograrse por medios morfosintácticos: por ejemplo, con cum:

Caes., B.C. III 24,3 quadrirremem cum remigibus suis.

Y habría otras preposiciones que cumplirian el mismo cometido. Según Milner ${ }^{14}$ habría preposiciones que "orientan" a un término de la frase convirtiéndolo en primera persona y otras que lo hacen a la contrapuesta:

Cic., Fam. XV 2,2 Pisonem nostrum merito eius amo.

Parece muy sugestiva la tesis de Milner. En todo caso, hay que subordinarla a las reglas que hemos establecido como básicas, porque la

${ }^{14}$ En pp. 82-83. 
preposición parece que supone sólo la formalización, todavía no sistematizada ni consolidada, de aquéllas, puesto que hemos encontrado pasajes que contradicen su propuesta.

Lo específico de las tres últimas situaciones o comportamientos en el uso de is/se debe inscribirse en la razón que preside todo el hecho. Asi, las preposiciones, con intervención de la semántica, no hacen sino aclarar y reforzar la tesitura empráctica del acto de habla. Y si relacionamos esto con el dato obtenido en nuestra lectura de los prosistas latinos, a saber, que hay determinados casos (no muchos, por supuesto) en los que el empleo de is o de se es potestativo, parece razonable pensar que, en tales momentos, el autor se orienta y encamina a través de criterios sintácticos. Ahora bien, estos criterios morfosintácticos, complementarios y, en algún caso, hasta sustitutos de los emprácticos, se presentan en el proceso de sustitución en diversos grados según autor, tipo de obra e intención de la misma, no sólo en función de la época. Así, Gayo (por poner un ejemplo espectacular) se parece más en el uso del reflexivo a nuestra situación actual que a un autor como Suetonio, pese a su proximidad en el tiempo.

Nuestra crítica a trabajos como el de Bertocchi-Casadio y el propósito de llevar a cabo un estudio rigurosamente gramatical, sin conceptos ni teorías preadquiridas que enturbien la visión del problema, no quiere decir que nos desentendamos de cualquier tesis aprovechable. Bien se ve que nuestro tratamiento no es ajeno a las preocupaciones actuales de la Pragmática Lingüística y que nuestro afán de tomar pasajes más amplios que algunos de los utilizados por nuestros antecesores para tratar de entender mejor la situación empráctica no es ajeno a uno de los postulados más conocidos de la Lingüística del Texto.

\section{J. M. Requejo}

\section{BIBLIOGRAFÍA}

Benedicto, E. (1989): "El reflexivo indirecto en latín», Actas del VII Congreso Español de Estudios Clásicos, Madrid, pp. 411-417.

Bertocchi, A., y Casadio, C. (1983): "Anaphoric relations, pronoun and latin complementation», Latin linguistics and linguistic theory, Amsterdam-Filadelfia, pp. 27-39.

Bühler, K. (1967) : Teoria del Lenguaje, Madrid.

Dahlén, E. (1964): Études syntaxiques sur les pronoms réfléchis pléonastiques en latin, Gotemburgo.

Enríquez, J. A. (1984): "Verbos impersonales de sentimiento», Faventia 6, 2, pp. 25-32.

Ernout, A., y Thomas, F. (1972 $)$ : Syntaxe latine, París. 
Fruyt, M. (1987): «Interprétation sémantico-référentielle du réfléchi latin», Glotta 65 , pp. 204-221.

Garcia Calvo, A. (1979): Del lenguaje, Madrid.

-.. (1983): De la construcción, Madrid.

Giannecchini, G. (1980-81): "Considerazioni sul riflessivo latino", AFLPer 18, 3, pp. 15-32.

Kühner, R., y Stegmann, K. (1966 = 1912): Ausführliche Grammatik der lateinischen Sprache, Hannover.

Milner, J. C. (1978): "Le système du réfléchi en latin», Langages 50, pp. 73-85.

Orlandini, A. (1987): "Pour un analyse des pronoms personnels latins. Un analyse de $i s », I G 34$, pp. 9-14.

- (1989): "Les pronoms possessifs et personnels en latin», IF 94, pp. 177-189.

Riemann, O. (1942,): Syntaxe latine, París.

Ronconi, A. (1959): La sintassi latina, Florencia.

Scherer, A. (1975): Handbuch der lateinischen Syntax, Heidelberg.

Serbat, G. (1988): "Aperçu sur la déixis et l'anaphore», Linguistique latine et linguistique générale, Lovaina la Nueva, pp. 23-28.

Stolz, F., y Schmalz, J. H. (1910 $)$ : Lateinische Grammatik, Munich.

Szantyr, A. (1965): Lateinische Syntax und Stilistik, Munich.

Tovar, A. (1946): Gramática histórica latina. Sintaxis, Madrid.

Woodcock, E. C. (1971): A New Latin Syntax, Londres. 